\title{
A case of cryptogenic thoracic aortic aneurysm with tetralogy of Fallot
}

Satoshi Miyairi, MD, Masaaki Koide, MD, and Yoshifumi Kunii, MD

\begin{abstract}
A 28-year-old woman was diagnosed with Down syndrome and tetralogy of Fallot during infancy. As a first operation, palliative right ventricular outflow tract repair was performed. Two years after that operation, at the age of 3 years, the patient underwent intracardiac repair. She was followed up as an outpatient for chronic heart failure with residual ventricular septal defect, and pulmonary valve stenosis.

Twenty-five years after the intracardiac repair, the patient's chest radiograph showed an enlarged superior mediastinum, and computed tomography revealed an aortic arch aneurysm of unknown etiology (Figure 1). The huge saccular aortic aneurysm was located in the distal aortic arch, and it displaced the left subclavian artery posterolaterally. The patient successfully underwent a planned operation of partial arch replacement, reoperative right ventricular outflow tract repair, and residual ventricular septal defect closure. The postoperative course was uneventful, and she was discharged home on postoperative day 20.
\end{abstract}

From Seirei Hamamatsu General Hospital, Hamamatsu-city, Japan.

Disclosures: Authors have nothing to disclose with regard to commercial support.

Received for publication June 26, 2013; accepted for publication July 8, 2013; available ahead of print Aug 29, 2013

Address for reprints: Satoshi Miyairi, MD, Department of Cardiovascular Surgery, Seirei Hamamatsu General Hospital Hamamatsu, 2-12-12, Sumiyoshi, Naka-ku,

Hamamatsu-city, Shizuoka, 430-8558 Japan (E-mail: sa_msa_m@yahoo.co.jp).

J Thorac Cardiovasc Surg 2014;147:1088

$0022-5223 / \$ 36.00$

Copyright (C) 2014 by The American Association for Thoracic Surgery

http://dx.doi.org/10.1016/j.jtcvs.2013.07.017

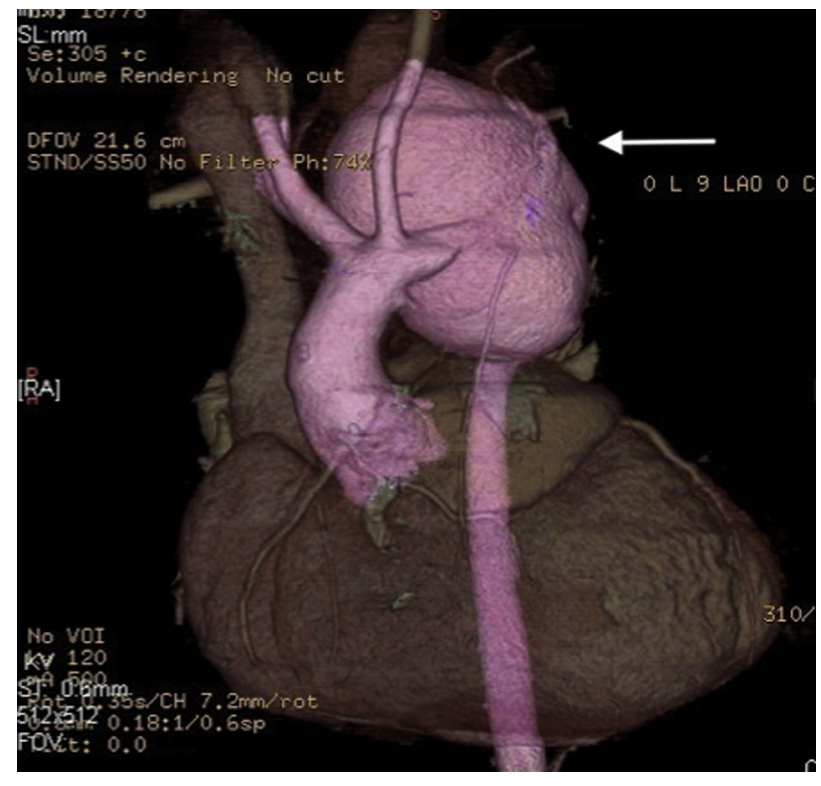

FIGURE 1. A huge saccular aneurysm can be seen at the distal arch, displacing the left subclavian artery (arrow). 